\title{
Mortality of children with sickle cell disease: a population study
}

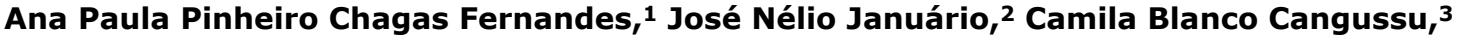 \\ Daniela Lino de Macedo, ${ }^{3}$ Marcos Borato Viana 4
}

\begin{abstract}
Objective: To describe the deaths of children with sickle cell disease (SCD) in Minas Gerais, Brazil, and followed up at the Fundação Hemominas.

Methods: Cohort of children diagnosed by the Neonatal Screening Program in Minas Gerais (March/1998 February/2005). Deaths were identified by searching for children who did not attend scheduled consultations at hemocenters. Clinical and epidemiological data were abstracted from death certificates, the newborn screening database, individual medical records, and from interviews with families.

Results: During the period, 1,833,030 newborns were screened; 1,396 had SCD $(1: 1,300)$. There were 78 deaths: 63 with SS genotype, 12 with SC genotype, and three with SB+ thalassemia genotype. Fifty-six children $(71.8 \%)$ died before 2 years of age; 59 died in hospitals and 18 at home or during transportation. Causes of death according to certificates $(n=78)$ : infections, $38.5 \%$; acute splenic sequestration, $16.6 \%$; other causes, $9 \%$; did not receive medical care, $15.4 \%$; and not identified on certificates, $20.5 \%$. According to interviews $(n=52)$, acute splenic sequestration was responsible for one third of deaths, in contrast with $14 \%$ recorded on death certificates. Survival probabilities at 5y (SEM) for children with SS, SC, and S $\beta^{+}$thalassemia were $89.4(1.4), 97.7(0.7)$, and $94.7 \%$ (3.0), respectively (SS vs. SC, p < 0.0001)

Conclusions: Even with a carefully controlled newborn screening program, the probability of SS children dying was still found to be high. Causes not identified on death certificates may indicate difficulties recognizing SCD and its complications. Educational campaigns directed at health professionals and SCD patients' families should be boosted in order to decrease SCD mortality.
\end{abstract}

J Pediatr (Rio J). 2010;86(4):279-284: Anemia, sickle cell, mortality, socioeconomic factors, health services.

\section{Introduction}

Sickle cell disease (SCD) is a genetic disorder of great epidemiological and clinical importance. Its hallmark is the inheritance of the $S$ beta-globin gene (gene $\beta^{s}$ ). This gene causes the $S$ variant of hemoglobin to be produced in red blood cells. Vaso-occlusive phenomena and chronic hemolysis are the main causes of the clinical manifestations of SCD and, while the primary abnormalities are restricted to erythrocytes, the result is a systemic disease that can affect any organ. ${ }^{1}$

SCD is an important public health problem in Brazil. It is estimated that the number of people with the sickle trait is $7,200,000$, with the prevalence in the general population being between 2 and $8 \% .{ }^{2}$ The incidence of the sickle trait in Minas Gerais is 3.3\% and the incidence of

1. Núcleo de Ações e Pesquisa em Apoio Diagnóstico (NUPAD), Faculdade de Medicina, Universidade Federal de Minas Gerais (UFMG), Belo Horizonte, MG, Brazil.

2. NUPAD, Faculdade de Medicina, UFMG, Belo Horizonte, MG, Brazil. Professor assistente, Departamento de Clínica Médica, UFMG, Belo Horizonte, MG, Brazil.

3. NUPAD, Faculdade de Medicina, UFMG, Belo Horizonte, MG, Brazil. Acadêmica, Curso de Medicina, UFMG, Belo Horizonte, MG, Brazil.

4. NUPAD, Faculdade de Medicina, UFMG, Belo Horizonte, MG, Brazil. Professor titular, Departamento de Pediatria, UFMG, Belo Horizonte, MG, Brazil.

Support: Núcleo de Ações e Pesquisa em Apoio Diagnóstico (NUPAD), Faculdade de Medicina, Universidade Federal de Minas Gerais (UFMG), Belo Horizonte, MG, Brazil; Conselho Nacional de Desenvolvimento Científico e Tecnológico (CNPq) - The last author receives a grant from the agency providing financial support; the study has been partially supported by CNPq (protocol MCT/CNPq/MS-SCTIE-DECIT nº 026/20).

No conflicts of interest declared concerning the publication of this article.

Suggested citation: Fernandes AP, Januário JN, Cangussu CB, de Macedo DL, Viana MB. Mortality of children with sickle cell disease: a population study. J Pediatr (Rio J). 2010;86(4):279-284.

Manuscript submitted Dec 28 2009, accepted for publication Mar 102010.

doi:10.2223/JPED.2005 
SCD is approximately $1: 1,400$ newborn infants screened, according to data from the - Minas Gerais State Newborn Screening Program (Programa Estadual de Triagem Neonatal de Minas Gerais, PETN-MG), which began screening for hemoglobinopathies in March of 1998. The PETN-MG includes all of the municipal authorities in the state of Minas Gerais, and coverage is $94 \%$ of live births. ${ }^{3}$

Although SCD leads to elevated morbidity and mortality, particularly during the first 5 years of life, ${ }^{4-9}$ mortality has been reducing among children with SCD less than ten years old. ${ }^{10-14}$ In 1970, median survival was 20 years among citizens of the United States with the homozygous form (SS). ${ }^{15}$ After initiating programs for neonatal diagnosis, education and integrated patient care, SS children had an $85 \%$ chance of survival at the age of 20.4

Despite the fact that the majority of SCD genotypes cause reduced life expectancy, sickle cell anemia, which is the presence of homozygosis for hemoglobin $S$, is the most common genotype and has the most severe clinical presentation. Several different studies have shown that the incidence of deaths is greater and survival is reduced among patients with sickle cell anemia. $4,9,16,17$ The primary causes of death before 10 years of age include infections and acute splenic sequestration. ${ }^{4,16-23}$

The objective of this study was to perform a detailed investigation of the causes and circumstances of the deaths of children with SCD identified by the PETN-MG screening program. This is the first time that a population cohort has been used for this purpose in Brazil. Understanding the various different determinants of these deaths should facilitate the planning of public policies and other actions that can contribute towards reducing morbidity and mortality and improving the quality of life of people with SCD.

\section{Methods}

The study population comprised children diagnosed with SCD by the PETN-MG screening program and treated at Fundação Hemominas hemocenters who died between the 1st of March of 1998 and the 28th of February of 2005.

The PETN-MG program has screened for SCD and other hemoglobinopathies since March of 1998. All of the state of Minas Gerais' 853 municipal authorities are included and coverage is $94 \%$ of live births. Blood samples are taken from newborn infants on their fifth day of life using filter paper and are sent to the neonatal screening laboratory at the Center for Actions and Research in Diagnostic Support (NUPAD - Núcleo de Ações e Pesquisa em Apoio Diagnóstico) at the medical faculty of the Universidade Federal de Minas Gerais (UFMG) in Belo Horizonte, Brazil, where the program's technical and operational headquarters are.

The information on patient deaths originates from investigations into the reasons why patients did not attend their consultations at the hemocenter. The NUPAD actively follows-up all patients who are diagnosed with SCD as part of the screening program and are being treated at the Fundação Hemominas, making it unnecessary to design a sampling strategy, since it can be stated with confidence that all deaths during the study period have been accounted for.

Data were extracted from the PETN-MG database and also from death certificates, from the Brazilian National Health Service's database (DATASUS), from the Brazilian Institute of Geography and Statistics' database (Instituto Brasileiro de Geografia e Estatística, IBGE), from medical records from outpatients clinics at the Fundação Hemominas and from interviews with children's carers. Cause, date and location of death were extracted from the 78 death certificates.

The NUPAD database was the source for information on family location and compliance with the follow-up protocol, since a copy of the notes from every consultation at the hemocenters is sent to the Control and Treatment Team at NUPAD. Since this was a retrospective study, there was no specific data collection phase designed to investigate compliance with prophylactic anti-infection measures (specific vaccines and antibiotics).

A semi-structured interview was conducted with each deceased child's parent or guardian during 2006, which was between 1 and 8 years after the child had died. The researcher responsible (APPCF) was obliged to visit 41 different towns, traveling around 10 thousand kilometers. Despite her best efforts, 24 families could not be located, primarily from the subset whose children had died more than 5 years previously. A further two families refused to be interviewed. The median duration of interviews was 25 minutes and four subjects were covered: 1 ) the circumstances relating to death; 2) SCD follow-up care and acute events other than that leading to death; 3 ) socioeconomic and cultural status; and 4) subjects' impressions of their experience of living with a child with SCD. All interviews were conducted after interviewees had read and signed an informed consent form that explained the study's objectives, procedures and possible benefits and costs.

A dedicated Microsoft Access database was designed specially for this study and used to input the data from Fundação Hemominas medical records.

For the statistical analysis, the frequencies of nominal variables were compared using the chi-square test, without correction for continuity, or Fisher's exact test when necessary. Survival curves were plotted using the Kaplan-Meier method, and curves were compared using the logrank test. All 78 deaths were defined as adverse events, irrespective of whether they were related to SCD or not. All children who were still alive on the 15th of February of 2005 ( $n=1,318$ ) were "censored" on that day. Results were considered significant if the probability of alpha error was $\leq 0.05$. 
This study was approved by the Research Ethics Committees at UFMG and the Fundação Hemominas and was awarded financial support by the Conselho Nacional de Desenvolvimento Científico e Tecnológico as part of an MCT/CNPq/MS-SCTIE-DECIT grant, number 026/20.

\section{Results}

During the period studied, $1,833,030$ newborn infants were screened by the PETN-MG, and 1,396 children had a hemoglobin profile compatible with SCD: 764 SS or SB0-thalassemia, 555 with hemoglobin SC disease, 10 with hemoglobin SD disease and 67 with $\mathrm{SB}^{+}$thalassemia (incidence of $1: 1,313$ for all forms, $1: 2,400$ for $S S / S \beta^{0}$ thalassemia and 1:3,300 for SC).

There were 78 deaths during the 7 -year period. Forty-one $(52 \%)$ of the children who died were male and $37(48 \%)$ were female. The majority of the deceased children lived in urban areas (78\%) and in small towns with populations of up to 50,000 inhabitants (56.4\%).

The median age at the time blood was taken for the screening test was 9 days, with $75 \%$ of the children being screened by 18 days. The median age at first consultation at the hemocenter was 2.1 months. Three children died before attending their first consultation at the hemocenter, aged 19,55 and 57 days. The cause of death was septicemia in two cases and was not identified in the third.

Figure 1 illustrates the distribution of deaths by age group. The majority of deaths $(71.8 \%)$ were before 2 years of age. Median age at death was 13.7 months.

Broken down by the hemoglobin profile detected by neonatal screening, 63 of the children who died had $\mathrm{SS} / \mathrm{SB}^{0}(80.8 \%), 12$ had SC $(15.4 \%)$ and three had $\mathrm{SB}^{+}$ thalassemia $(3.8 \%)$.

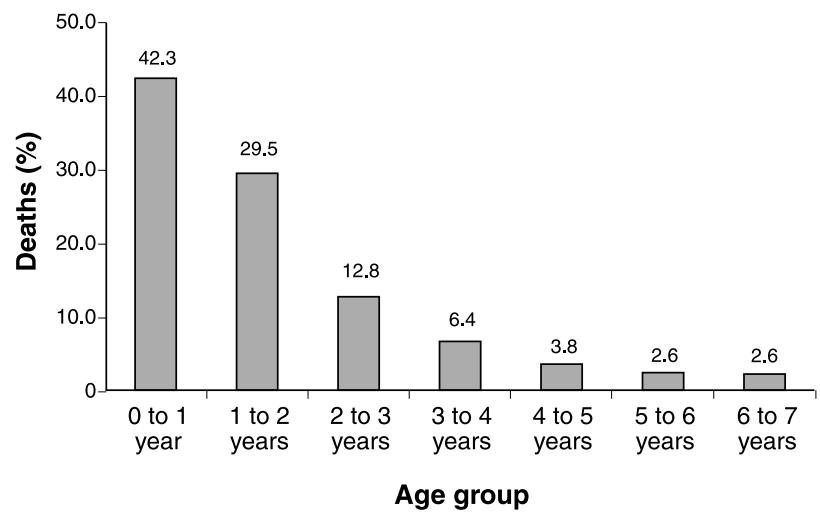

Figure 1 - Distribution by age group of 78 children with sickle cell disease who died between March of 1998 and February of 2005 (Minas Gerais State Neonatal Screening Program - PETN-MG)
According to the death certificate data, there was a higher prevalence of deaths in hospital (59 cases), but 15 deaths were at home, three in transit and one at a basic healthcare center.

Infection (including pneumonia and septicemia) was the predominant causa mortis registered on the death certificates, followed by acute splenic sequestration. Where records stated "no medical care" the cause of death was defined as unknown (Figure 2).

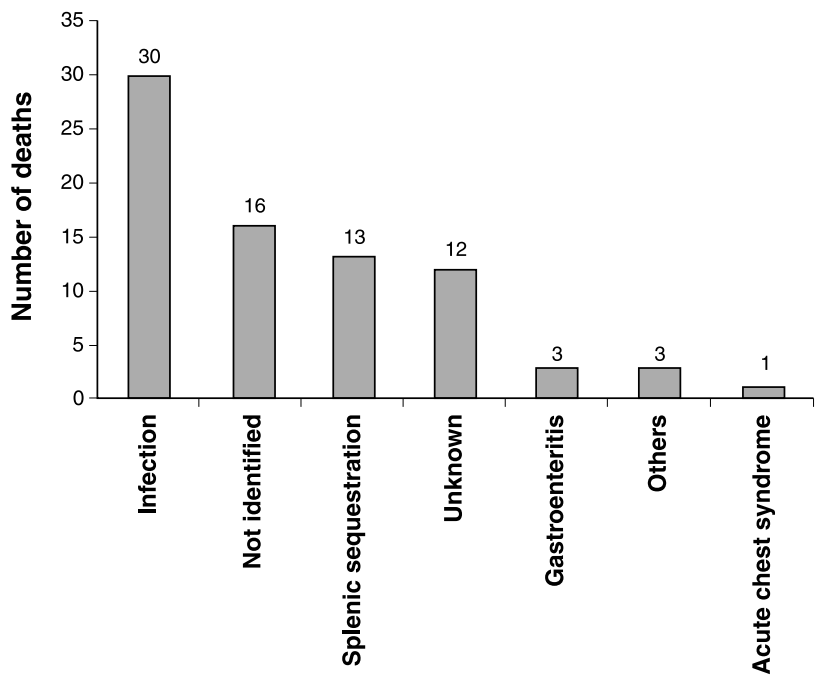

Figure 2 - Causes of death according to the death certificates of 78 children with sickle cell disease who died between March of 1998 and February of 2005, (Minas Gerais State Neonatal Screening Program - PETN-MG)

There was a certain degree of disagreement between the registered causes of death and the information provided by family members during the interviews $(n=52)$. For example, according to the death certificate data splenic sequestration caused seven of the 52 deaths (13.5\%), but according to the interviewees splenic sequestration was responsible for 16 of the 52 deaths (30.8\%).

Figure 3 illustrates the survival curves for children with hemoglobin SS disease or $\mathrm{SB}^{0}$-thalassemia, SC, SD and $\mathrm{SB}^{+}$thalassemia. The survival curve for children with $\mathrm{SS} / \mathrm{SB}^{0}$-thalassemia is significantly lower than the curve for children with SC ( $p<0.0001)$. The survival curve for children with $\mathrm{SS} / \mathrm{SB}^{0}$-thalassemia does not differ significantly from the curves for children with $\mathrm{SB}^{+}$thalassemia or $\mathrm{SD}$ ( $p=0.21$ and $p=0.36$, respectively). It was also observed that, during their first 5 years of life, children with SS/ $\mathrm{SB}^{0}$-thalassemia exhibited a more rapid reduction in their probability of survival than did children with $\mathrm{SC}$ and $\mathrm{SB}^{+}$ thalassemia (Table 1).

Out of the total number of consultations scheduled for the 78 children who died (580 consultations), $77.3 \%$ were attended and $22.7 \%$ were not. 


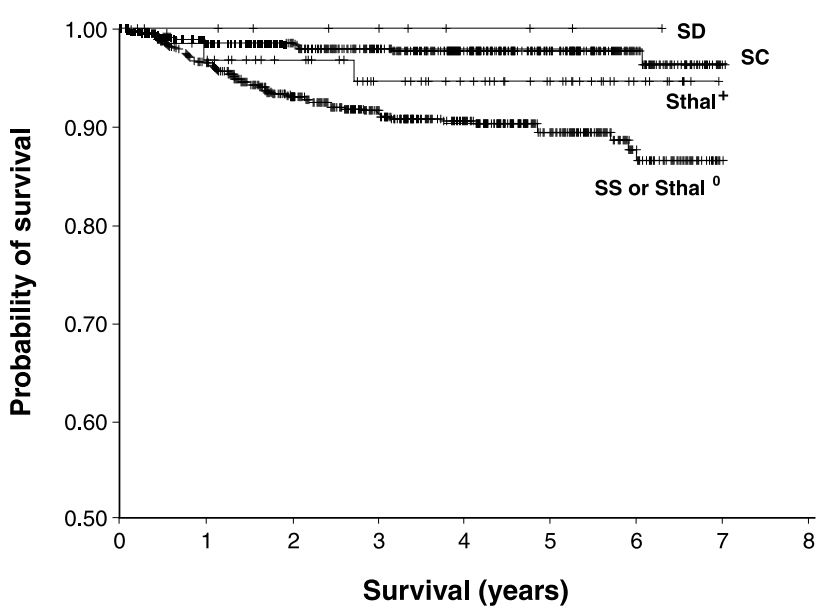

Figure 3 - Curves illustrating the estimated probability of survival of 1,396 children diagnosed between March of 1998 and February of 2005, broken down by type of hemoglobinopathy (Minas Gerais State Neonatal Screening Program - PETN-MG). The survival curves for children with $\mathrm{SS} / \mathrm{S} \beta^{0}$-thalassemia are significantly different from the curves for children with SC (KaplanMeier method, logrank test, $p<0.0001$ )

According to information from the interviews $(n=52)$, $57.7 \%$ of these children were seen within 6 hours of onset of the symptoms related to the event that caused their deaths, while $71.2 \%$ were seen within 24 hours and $17.3 \%$ died without receiving any medical care. In this subset, death occurred within 12 hours of the onset of symptoms in $55.8 \%$ of cases and within 24 hours in 67.3 . According to the interviewees, fever, pain, vomiting and prostration were the most common symptoms related to the event leading to death. Nineteen children were taken straight to hospital by their families (36.5\%), while basic healthcare centers were the first service sought by 12 (23\%) families and another six families first presented at walk-in centers (11.5\%). Forty-three families (82.7\%) reported that their children had been given antibiotic prophylaxis regularly, and 47 families (90.4\%) said their children were taking folic acid regularly. Twenty-one families (40.4\%) reported that their children had been given special immunobiologicals regularly. With relation to the children's clinical condition prior to death, $65 \%$ of the children had been admitted to hospital at least once previously and $19 \%$ of them had been admitted more than three times, while $67.3 \%$ of them had already suffered a pain crisis previous to death and 14 children (27\%) had already suffered acute splenic sequestration, with two of these suffering the event more than once.

With relation to the social and economic situation of the families who were interviewed $(n=52), 58 \%$ had a monthly per capita income of less than R\$100.00 $(R \$ 2.00=$ US $\$ 1.00)$ and for $20 \%$ of them this figure was less than $\mathrm{R} \$ 50.00$. The lowest reported per capita income was zero and the highest was $R \$ 380.00$. At the time of the interview the national minimum monthly wage was $\mathrm{R} \$ 350.00$. The mean number of family members was 5.6 and $76.8 \%$ of the mothers and $86.8 \%$ of the fathers had not completed primary education and $13.5 \%$ of the mothers and $19 \%$ of fathers were illiterate.

\section{Discussion}

The patient population studied here reflects the overall health status of children with SCD born in the Brazilian state of Minas Gerais, since the PETN-MG has a coverage of $94 \%$ of all infants born in $100 \%$ of the state's municipalities. All deaths among the subset of children diagnosed with SCD and being treated at the hemocenters were included in the analyses, meaning that the cases include all deaths from within this group of children that occurred within the study period, as is characteristic for a population-based study.

As has been observed in other reports, in this study there was no significant difference between the incidence of deaths in each sex within the age groups studied. 4,23 The greatest incidence of death $(80.8 \%)$ was among patients with $\mathrm{Hb}$ SS which is both the most common genotype and responsible for the most severe clinical presentation; and this has also been observed in other studies.4,9,16,17

Table 1 - Estimated probabilities of survival ( $\% \pm$ SE) of 1,396 children diagnosed between March of 1998 and February of 2005 , broken down by type of hemoglobinopathy and survival ( 1,3 and 5 years)

\begin{tabular}{lccc}
\hline & \multicolumn{3}{c}{ Estimated probability of survival } \\
\cline { 2 - 4 } Type of hemoglobinopathy ( $\mathbf{n}$ diagnosed) & $\mathbf{1}$ year & $\mathbf{3}$ years & $\mathbf{5}$ years \\
\hline SS or SB ${ }^{0}$-thalassemia $(n=764)$ & $96.6\left(0.7^{*}\right)$ & $91.6\left(1.1^{*}\right)$ & $89.4\left(1.4^{*}\right)$ \\
SC $(n=555)$ & $98.7\left(0.5^{*}\right)$ & $98.0\left(0.6^{*}\right)$ & $97.7\left(0.7^{*}\right)$ \\
SB+ thalassemia $(n=67)$ & $96.8\left(2.2^{*}\right)$ & $94.7(3.0 *)$ & $94.7\left(3.0^{*}\right)$ \\
SD $(n=10)$ & 100.0 & 100.0 & 100.0 \\
All $(n=1,396)$ & $97.5\left(0.4^{*}\right)$ & $94.3\left(0.7^{*}\right)$ & $93.1\left(0.8^{*}\right)$ \\
\hline
\end{tabular}

* Standard error of the mean. 
When deaths were distributed according to the child's age at death, a concentration of deaths can be observed before 2 years, in common with reports published by other authors.4,16,19,21 Follow-up data on children with SCD diagnosed by the neonatal screening programs of three US states and published by the Centers for Disease Control and Prevention (CDC) showed that the median age at death was 22 months. ${ }^{24}$ This elevated mortality during the first 5 years of life may be because of the greater incidence of severe acute events during early childhood. Three children died before reaching 2 months, and before attending their first consultation, from causes that were probably not related to the underlying diagnosis.

Although the majority of deaths occurred in hospital, it is nevertheless important to point out that almost one quarter of these children died at home or on their way to a healthcare service. Certain factors, such as living in rural areas and difficulties preventing families from identifying situations in which their children were at risk, may have contributed to this situation. A study conducted in England reported seven deaths at home out of a group of 11 SCD patients less than 20 years old. These authors stressed the need for rapid recognition of acute events and seeking medical attention promptly in order to counteract the rapidity with which the severe signs and symptoms of the disease develop. 25

The predominant cause of death in this study was infection, followed by acute splenic sequestration. Similar data have also been published by other authors.4,17-21,26,27 Notwithstanding, the numbers of unidentified and unknown causes of death were elevated. An unidentified cause of death suggests that healthcare teams have a certain difficulty in recognizing SCD and its acute complications, since the majority of certificates where the cause of death was not identified took place in hospital. The majority of cases in which cause of death was unknown were related to children who died before receiving medical care.

Comparison of the death certificate data with information provided in the 52 interviews revealed discrepancies, primarily with relation to acute splenic sequestration as cause of death. The apparent difficulty that healthcare teams have in recognizing splenic sequestration is noteworthy since this is one of the primary severe acute events characteristic of SCD in early childhood and its history and clinical presentation are very obvious. 26

Analysis of the survival curves showed that the probability of survival of children with $\mathrm{SS} / \mathrm{SB}^{0}$-thalassemia dropped more sharply during the first 5 years than the curve for $\mathrm{SC}$ children. The failure of the comparison between $\mathrm{S} \beta^{+}$ thalassemia and SD groups to attain statistical significance is probably due to the small number of children in each category.

The general mortality rate for under-5s in the state of Minas Gerais was 30.4 per thousand in 2000,28 which, subtracted the early neonatal mortality rate, results in an estimate of 18 per 1,000 for the purposes of making comparisons with the estimated probability of survival to 5 years in this study. The estimated mortality rate for SS children was 106 per 1,000 (10.6\%), i.e., around six times greater than the rate for the state. The survival curve for 310 SS children who took part in a Jamaican cohort study showed that first-year mortality was $6 \% .{ }^{5}$ In the Dallas cohort the probability of death by 6 years of age for SS/SBthalassemia children was $5 \% .{ }^{29}$ It should be pointed out, however, that the area covered by the study was restricted to the Northeast of Texas and that enrollment on the study only took place after attendance at a first consultation at the Comprehensive Sickle Cell Center (median of 4.2 months) rather than after laboratory diagnosis of the newborn (with sensitivity close $100 \%$ ), which obviously underestimates the true probability of death in the population.

In the majority of cases, medical care was received within the first 6 hours after onset of symptoms. There was, therefore, no major delay in seeking medical attention. Twenty-three percent of these cases were seen at basic healthcare centers, which is because of the large number of children who live in small towns. The high reported compliance with antibiotic prophylaxis should be treated with skepticism since a study was undertaken into this specific subject at the Hemocenter de MG and found that compliance is well below this figure. ${ }^{30}$ It can be concluded that the most significant difficulties that may have contributed to these deaths are related to the medical attention itself, i.e. the healthcare teams' levels of capacity and training for dealing with acute SCD events and the resources available at the health services where patients first present. Another factor that should be considered is the speed with certain clinical presentations progress. The low educational level of parents and low family incomes are further obstacles.

The most important limitation of this study is its retrospective nature, since the clinical follow-up protocol was designed for treatment and not for research. The failure to interview families in one third of the cases was also a result of the retrospective cohort design, since the more time has passed, the more difficult it becomes to locate them. Since the main objective of the interviews had been to ask how the deaths took place, adding a qualitative element to the study that is more refined and humanized than merely inspecting death certificates and medical records, we do not believe that failing to interview 26 of 78 families compromised the study objectives.

These results indicate that in SCD social factors are strongly associated with the biological determinants and make a decisive contribution to the morbidity and mortality of the disease. The problems related to SCD are not therefore limited to technical issues, but are, indeed, also a social and political issue. The Ministry of Health's program to provide integrated healthcare for people with SCD is an ideal 
towards which patients, their families and the professionals involved in treating them must work in order to achieve the objective of improving the current living conditions and health status of these people.

It was concluded that even in the context of a neonatal screening program with rigorously controlled treatment, during the 7 first years of the PETN-MG the probability of death before 5 years of age was much greater among SS children than the overall mortality rate for this age group. Unidentified causes of death indicate that there are difficulties in recognizing SCD and its complications. Educational campaigns aimed at health professionals and at SCD patients' families should be stepped up in order to reduce the mortality and morbidity caused by SCD. Capacitating the basic healthcare centers should be made a priority, since simple interventions, such as neonatal screening, prophylactic penicillin, immunization and education can have a great impact on public health. Many deaths could be avoided through educating and by improving the social, economic and cultural conditions of the families of children with SCD.

\section{Acknowledgements}

We are indebted to the families who, despite all of the suffering involved in losing a child, were willing to discuss the events related to their children's deaths.

We are grateful to the Conselho Nacional de Desenvolvimento Científico e Tecnológico (CNPq) who financed this project as part of grant MCT/CNPq/MS-SCTIEDECIT, number 026/20.

We are also grateful to NUPAD-UFMG, in particular to the members of the Control and Treatment Team, for their professional dedication and for supporting this study.

\section{References}

1. Serjeant GR. Sickle cell disease. 2nd ed. Oxford: Oxford University Press; 1992.

2. Cançado RD, Jesus JA. A doença falciforme no Brasil. Rev Bras Hematol Hemoter. 2007;29:204-6.

3. Januario J. Incidência da doença falciforme em um milhão de nascidos vivos em Minas Gerais (1998-2001) [dissertação]. Belo Horizonte: Universidade Federal de Minas Gerais; 2002.

4. Leikin SL, Gallagher D, Kinney TR, Sloane D, Klug P, Rida W. Mortality in children and adolescents with sickle cell disease. Cooperative Study of Sickle Cell Disease. Pediatrics. 1989;84:500-8.

5. Serjeant GR. Natural history and determinants of clinical severity of sickle cell disease. Curr Opin Hematol. 1995;2:103-8.

6. Lee A, Thomas P, Cupidore L, Serjeant B, Serjeant G. Improved survival in homozygous sickle cell disease: lessons from a cohort study. BMJ. 1995;311:1600-2.

7. Koko J, Dufillot D, M'Ba-Meyo J, Gahouma D, Kani F. Mortality of children with sickle cell disease in a pediatric department in Central Africa. Arch Pediatr. 1998;5:965-9.

8. Thomas C, Lemerle S, Bernaudin F, Feingold J, Guillou-Bataille M, Reinert P. Sickle cell anemia: study of the pediatric mortality in Ile de France from 1985 to 1992. Arch Pediatr. 1996;3:445-51.

9. Platt OS, Brambilla DJ, Rosse WF, Milner PF, Castro O, Steinberg $\mathrm{MH}$, et al. Mortality in sickle cell disease. Life expectancy and risk factors for early death. N Engl J Med. 1994;330:1639-44.
10. Bainbridge $\mathrm{R}$, Higgs DR, Maude GH, Serjeant GR. Clinical presentation of homozygous sickle cell disease. J Pediatr. 1985;106:881-5.

11. Powars D, Chan LS, Schroeder WA. The variable expression of sickle cell disease is genetically determined. Semin Hematol. 1990;27:360-76.

12. Vichinsky E, Hurst D, Earles A, Kleman K, Lubin B. Newborn screening for sickle cell disease: effect on mortality. Pediatrics. 1988;81:749-55.

13. Zarkowsky HS, Gallagher D, Gill FM, Wang WC, Falletta JM, Lande $W M$, et al. Bacteremia in sickle hemoglobinopathies. J Pediatr. 1986;109:579-85

14. Yanni E, Grosse SD, Yang Q, Olney RS. Trends in pediatric sickle cell disease-related mortality in the United States, 1983-2002. J Pediatr. 2009;154:541-5.

15. Scott RB. Health care priority and sickle cell anemia. JAMA. $1970 ; 214: 731-4$

16. Thomas AN, Pattison C, Serjeant GR. Causes of death in sicklecell disease in Jamaica. Br Med J. 1982;285:633-5.

17. Manci EA, Culberson DE, Yang YM, Gardner TM, Powell R, Haynes $\mathrm{J} \mathrm{Jr}$, et al. Causes of death in sickle cell disease: an autopsy study. $\mathrm{Br}$ J Haematol. 2003;123:359-65.

18. Seeler RA. Deaths in children with sickle cell anemia. A clinical analysis of 19 fatal instances in Chicago. Clin Pediatr (Phila). 1972;11:634-7.

19. Diggs L. Anatomic lesions in sickle cell disease. In: Abramson $\mathrm{H}$, Bertles JH, Wethers D, editors. Sickle cell disease: diagnosis, management, education and research. Saint Louis: CV Mosby; 1973. p. 189-229.

20. Miller ST, Sleeper LA, Pegelow CH, Enos LE, Wang WC, Weiner $\mathrm{S}$, et al. Prediction of adverse outcomes in children with sickle cell disease. N Engl J Med. 2000;342:83-9.

21. Gill FM, Sleeper LA, Weiner SJ, Brown AK, Bellevue R, Grover $R$, et al. Clinical events in the first decade in a cohort of infants with sickle cell disease. Cooperative Study of Sickle Cell Disease. Blood. 1995;86:776-83.

22. Rogers DW, Clarke JM, Cupidore L, Ramlal AM, Sparke BR, Serjeant GR. Early deaths in Jamaican children with sickle cell disease. $\mathrm{Br}$ Med J. 1978;1:1515-6.

23. Shankar SM, Arbogast PG, Mitchel E, Cooper WO, Wang WC, Griffin MR. Medical care utilization and mortality in sickle cell disease: a population-based study. Am J Hematol. 2005;80:262-70.

24. Centers for Disease Control and Prevention (CDC). Mortality among children with sickle cell disease identified by newborn screening during 1990-1994 - California, Illinois, and New York. MMWR Morb Mortal Wkly Rep. 1998;47:169-72.

25. Gray A, Anionwu EN, Davies SC, Brozovic M. Patterns of mortality in sickle cell disease in the United Kingdom. J Clin Pathol. $1991 ; 44: 459-63$

26. Resende PV, Viana MB, Murao M, Chaves AC, Ribeiro AC. Acute splenic sequestration in a cohort of children with sickle cell anemia. J Pediatr (RJ). 2009;85:163-9.

27. Van-Dunem JC, Alves JG, Bernardino L, Figueiroa JN, Braga C, Nascimento Mde L, et al. Factors associated with sickle cell disease mortality among hospitalized Angolan children and adolescents. West Afr J Med. 2007;26:269-73.

28. Programa das Nações Unidas para o Desenvolvimento. Atlas do Desenvolvimento Humano no Brasil. Brasília: PNUD-Brasil; 2002. http://www.pnud.org.br/atlas. Access: 23/05/2006.

29. Quinn CT, Rogers ZR, Buchanan GR. Survival of children with sickle cell disease. Blood. 2004;103:4023-7.

30. Bitarães EL, Oliveira BM, Viana MB. Compliance with antibiotic prophylaxis in children with sickle cell anemia: a prospective study. J Pediatr (Rio J). 2008;84:316-22

\section{Correspondence:}

Marcos Borato Viana

Faculdade de Medicina, Departamento de Pediatria,

Universidade Federal de Minas Gerais

Av. Alfredo Balena, 190/267

CEP 30130-100 - Belo Horizonte, MG - Brazil

Tel.: + 55 (31) 3409.9772

Fax: +55 (31) 3409.9770

E-mail: vianamb@gmail.com 